\title{
Effect of forkhead box 01 (FOXO1) on beta cell development in the human fetal pancreas
}

\author{
M. Al-Masri • M. Krishnamurthy • J. Li • G. F. Fellows • \\ H. H. Dong • C. G. Goodyer $\cdot$ R. Wang
}

Received: 12 July 2009 /Accepted: 10 November 2009/Published online: 24 December 2009

(C) Springer-Verlag 2009

\begin{abstract}
Aims/hypothesis Recent studies have demonstrated that in adult murine beta cells the forkhead box O1 (FOXO1) transcription factor regulates proliferation and stress resistance. However, the role of FOXO1 during pancreatic development remains largely unknown. The present study aimed to characterise the expression of the FOXO1
\end{abstract}

Electronic supplementary material The online version of this article (doi:10.1007/s00125-009-1632-0) contains supplementary material, which is available to authorised users.

M. Al-Masri $\cdot$ M. Krishnamurthy $\cdot$ J. Li $\cdot$ R. Wang

Children's Health Research Institute,

University of Western Ontario,

London, ON, Canada

M. Al-Masri $\cdot$ J. Li $\cdot$ R. Wang

Department of Physiology/Pharmacology,

University of Western Ontario,

London, ON, Canada

G. F. Fellows

Department of Obstetrics and Gynecology,

University of Western Ontario,

London, ON, Canada

H. H. Dong

Children's Hospital of Pittsburgh,

University of Pittsburgh School of Medicine,

Pittsburgh, PA, USA

\section{G. Goodyer}

Department of Pediatrics, McGill University,

Montreal, QC, Canada

\section{R. Wang $(\bowtie)$}

Victoria Research Laboratories,

Room A5-140, 800 Commissioners Road East,

London, ON, Canada N6C 2V5

e-mail: rwang@uwo.ca transcription factor in the early to mid-gestation human fetal pancreas and to understand its role in islet cell development.

Methods Human (8-21 week fetal age) pancreases were examined using immunohistological, quantitative RT-PCR and western blotting. Isolated human (18-21 week) fetal islet epithelial cell clusters were treated with insulin or glucose, or transfected with $\mathrm{FOXO1}$ small interfering RNA (siRNA).

Results Nuclear and cytoplasmic FOXO1 were widely produced during human fetal endocrine pancreatic development, co-localising in cells with the transcription factors pancreatic and duodenal homeobox 1 (PDX-1) and neurogenin 3 (NGN3) as well as cytokeratin 19 (CK19), insulin and glucagon. Treatment with exogenous insulin $(50 \mathrm{nmol} / \mathrm{l})$ induced the nuclear exclusion of FOXO1 in both cytokeratin $19(\mathrm{CK} 19)^{+}(p<0.01)$ and insulin ${ }^{+}$cells $(p<0.05)$ in parallel with increased phospho-Akt $(p<0.05)$ production. siRNA knockdown of $F O X O 1$ significantly increased the number of $\mathrm{NGN}^{+}(p<0.01)$ and NK6 homeobox 1 (NKX6-1) $(p<0.05)$ cells in parallel with increases in insulin gene expression $(p<0.03)$ and $\mathrm{C}$-peptide ${ }^{+}$cells $(p<0.05)$ and reduced levels of hairy and enhancer of split 1 (HES1) $(p<0.01)$.

Conclusions/interpretation Our results indicate that FOXO1 may negatively regulate beta cell differentiation in the human fetal pancreas by controlling critical transcription factors, including NGN3 and NKX6-1. These data suggest that the manipulation of FOXO1 levels may be a useful tool for improving cell-based strategies for the treatment of diabetes.

Keywords Human fetal pancreas · Human islet epithelial cell clusters · Islet transcription factors · Nuclear FOXO1 . FOXO1 siRNA 


$\begin{array}{ll}\text { Abbreviations } \\ \text { CK19 } & \text { Cytokeratin 19 } \\ \mathrm{e} & \text { Mouse embryonic day } \\ \text { FOXA2 } & \text { Forkhead box A2 } \\ \text { FOXO1 } & \text { Forkhead box O1 } \\ \text { HES1 } & \text { Hairy and enhancer of split 1 } \\ \text { ISL1 } & \text { ISL LIM homeobox 1 } \\ \mathrm{n} & \text { Nuclear } \\ \text { NGN3 } & \text { Neurogenin 3 } \\ \text { NKX2-2 } & \text { NK2 homeobox 2 } \\ \text { NKX6-1 } & \text { NK6 homeobox 1 } \\ \text { PAX6 } & \text { Paired box genes 6 } \\ \text { PDX-1 } & \text { Pancreatic and duodenal homeobox 1 } \\ \text { PI3 } & \text { Phosphatidylinositol 3 } \\ \text { qRT-PCR } & \text { Quantitative RT-PCR } \\ \text { siRNA } & \text { Small interfering RNA }\end{array}$

\section{Introduction}

Pancreatic islet cell transplantation is a potential treatment for diabetes, but is limited by a shortage of donor material [1]. Determining the factors which regulate development of the human pancreas and maintain survival and function of islets may help devise cell-based strategies for diabetes treatment. One such research focus is aimed at better understanding the role of transcription factor cascades [2].

Several studies have suggested that the forkhead box (FOXO) transcription factors are key regulators of pancreatic beta cell function. In mammals, four $\mathrm{O}$ class members encoded by distinct genes have been identified including FOXO1, FOXO3, FOXO4 and FOXO6 [3]. FOXO1, also known as FKHR, is the most abundant isoform in the adult pancreas, where it is exclusively produced in beta cells $[4,5]$. Transcriptional activation of FOXO proteins is negatively regulated by insulin and growth factor-dependent activation of the phosphatidylinositol 3 (PI3)-kinase/Akt signalling cascade [6]. Activation of Akt results in the phosphorylation of FOXO proteins on conserved serine/threonine residues, leading to nuclear exclusion and subsequent degradation. Withdrawal of insulin or growth factors stimulates dephosphorylation and nuclear translocation of FOXO proteins, leading to FOXO-induced gene-specific transcriptional activation [6].

In the mouse pancreas, FOXO1 competes with forkhead box A2 (FOXA2) for binding to the pancreatic and duodenal homeobox 1 ( $P d x-1$ [also known as $P d x l$ ]) promoter, and, subsequently, acts as a negative regulator of PDX-1 production [7]. Moreover, under oxidative stress conditions, PDX-1 translocates to the cytoplasm of beta cells while FOXO1 moves into the nucleus, resulting in a restriction of beta cell growth and proliferation in order to prevent cellular damage [8]. This differential nuclear vs cytoplasmic localisation of FOXO1 and PDX-1 has been shown in HIT-T15 cells to work through the c-Jun N-terminal kinase pathway [8]. The presumption that FOXO1 protects against beta cell failure has been further supported by studies demonstrating its ability to increase neurogenic differentiation 1 (NEUROD) and v-maf musculoaponeurotic fibrosarcoma oncogene homologue A (MAFA) production, a compensatory response that preserves beta cell function under metabolic stress conditions [9].

During mouse pancreatic organogenesis, FOXO1 and PDX-1 share similar production patterns; both are widely produced in the pancreatic epithelium between embryonic day (e) 9.5 and 14.5 and become exclusively produced postnatally in beta cells [10-14]. More recently, FOXO1 has been reported in murine myoblasts to interact with Notch signalling to regulate hairy and enhancer of split 1 (Hes1) gene expression; HES1 is a well-known repressor of neurogenin 3 ( $\mathrm{Ngn} 3$ [also known as Neurog3]) [15, 16]. These findings suggest that FOXO1 may be involved at multiple steps of murine pancreatic organogenesis [12]. However, while the role of FOXO1 in adult murine pancreatic tissue has been well characterised, little is known of its contributions during islet development. Mouse embryos lacking FOXO1 demonstrate incomplete vascular development and do not survive beyond e10.5 [17]. Because of this early lethality, the role of FOXO1 during pancreatic organogenesis has not been thoroughly investigated.

The goal of the present study was to characterise the pattern of FOXO1 production during human fetal pancreas development (8-21 week fetal age) and to identify its function in early islet cell specification. We demonstrate that FOXO1 is widely produced in the endocrine pancreas from the earliest age examined ( 8 weeks) and is readily detectable in $>75 \%$ of cytokeratin 19 (CK19) $^{+}$, insulin ${ }^{+}$, glucagon ${ }^{+}, \mathrm{PDX}_{-1}{ }^{+}$and $\mathrm{NGN}^{+}$cell populations from 8 to 21 weeks. To verify if FOXO1 is functional in the pancreas at this stage, isolated islets (18-21 weeks) were challenged with $50 \mathrm{nmol} / 1$ insulin, leading to a significant increase in phospho-Akt production and nuclear exclusion of FOXO1. Moreover, small interfering RNA (siRNA) knockdown of FOXO1 in the isolated islets significantly decreased HES1 expression in parallel with increases in NGN3, NK6 homeobox 1 (NKX6-1) and insulin gene expression and cell populations, indicating that FOXO1 may negatively control beta cell differentiation in the human fetal pancreas. These data suggest that future investigations involving the genetic or pharmacological manipulation of FOXO1 may prove useful for the regeneration of beta cells for islet transplantation purposes. 


\section{Methods}

Pancreatic tissue collection and cell culture

Human fetal pancreatic tissues (8-21 week fetal age) were collected according to protocols approved by the Health Sciences Research Ethics Board at the University of Western Ontario and the Research Ethics Board of the Royal Victoria Hospital at the McGill University Health Centre, in accordance with guidelines of the Canadian Council on Health Sciences Research Involving Human Subjects. Tissues were immediately processed for immunohistology, RNA or protein extraction, with a minimum of three pancreases per age group [18].

Fetal pancreatic tissues from 18-21 week fetal age, a period when they contain abundant small islets [18], were dissected and immediately digested using a dissociation buffer containing collagenase V $(1 \mathrm{mg} / \mathrm{ml})$ (Sigma, St Louis, MO, USA) at $37^{\circ} \mathrm{C}$ for $30 \mathrm{~min}$. The isolated islets, containing mostly undifferentiated epithelial cells (PDX- $1^{+}$/ $\mathrm{CK}_{1} 9^{+}$cells) with a few scattered or clustered endocrine cells [19], were plated onto 12 well plates (Corning/VWR, Toronto, ON, Canada) and cultured in CMRL1066 medium containing 10\% (vol./vol.) FBS (Invitrogen, Burlington, ON, Canada).

Treatment of islets with insulin or glucose Freshly isolated islets from 18-21 week fetal pancreases were plated in 12 well plates in CMRL1066 medium with $10 \%$ (vol./vol.) FBS and subsequently treated with either insulin $(0,10,25$, 50 or $100 \mathrm{nmol} / \mathrm{l})$ or glucose $(5.5,10$ or $25 \mathrm{mmol} / \mathrm{l}$ ) (Sigma) and cultured for $24 \mathrm{~h}$.

Transient transfection of FOXO1 siRNA Freshly isolated islets from 18-21-week-old fetal pancreases were recovered overnight in CMRL1066 containing 10\% (vol./vol.) FBS and transiently transfected with $60 \mathrm{nmol} / 1$ human FOXO1 siRNA (sc-35382) or control siRNA (sc-37007, proprietary sequence) commercially obtained from Santa Cruz Biotechnology (Santa Cruz, CA, USA), using an siRNA transfection kit $[19,20]$. A pool of three sequences for human FOXO1 siRNA (Santa Cruz Biotechnology) was used (Electronic supplementary material [ESM] Table 1). Islet epithelial cell clusters were harvested at 24 and $48 \mathrm{~h}$ following transfection. Transfection efficiency was monitored using fluorescein-conjugated control siRNA (Santa Cruz Biotechnology) and quantitative RT-PCR (qRT-PCR) analysis for $\mathrm{FOXO1}$ mRNA, with approximately $60 \%$ of the islet epithelial cluster cells being transfected, as described previously [19-22].

At the end of the culture period, islets were harvested and processed for protein or RNA extraction or fixed for immunocytochemistry studies. Three to six fetal pancreatic isolations per experimental group were used for analyses, with an average of 2,000 cells counted each time.

Immunofluorescent and morphometric analyses

Pancreatic tissues and islets were fixed in 4\% (vol./vol.) paraformaldehyde. Cell pellets were embedded in $2 \%$ (wt/vol.) agarose, followed by paraffin embedding [23]. Some pancreases were embedded using a frozen tissue matrix. Sections $(5 \mu \mathrm{m})$ were cut throughout the entire length of the pancreas and were stained with appropriate dilutions of primary antibodies (ESM Table 2). FITC- and Texas Red-labelled secondary antibodies were obtained from Jackson Immunoresearch Laboratories (West Grove, PA, USA). Images were recorded by a Leica DMIRE2 fluorescence microscope (Leica, Richmond Hill, ON, Canada) with Openlab image software (Improvision, Lexington, MA, USA).

Immunofluorescence staining for FOXO1 showed that FOXO1 is present in both the nucleus and cytoplasm of ductal and endocrine cells during human fetal pancreas development. Since FOXO1 levels in the nucleus (nFOXO1) have been shown to be indicative of biological activity [9], the morphometric analyses focused on nFOXO1. To identify co-localisation of nFOXO1 with other pancreatic transcription factors as well as epithelial and endocrine cell markers, double immunofluorescence staining was performed. Co-localisation of nFOXO1 with PDX-1, NGN3, CK19, insulin or glucagon was quantified by counting double-labelled cells. Changes in nFOXO1 in proliferating cells were assessed by counting double-labelled cells for nFOXO1 with Ki67. At least 1,000 cells per ductal region $\left(\mathrm{CK} 19^{+}\right.$cells) and 500 cells per endocrine region (insulin ${ }^{+}$or glucagon ${ }^{+}$cells) were counted per pancreas, except at 8-12 weeks of fetal age, where all cells were counted. Data are expressed as percentage of $\mathrm{nFOXO}^{+}$cells within the total number of

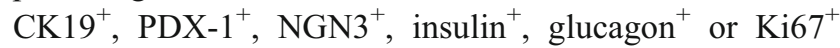
cells counted [18].

Protein extraction and western blot analysis

Total protein from human fetal pancreatic tissues and isolated fetal islets was extracted by sonication in Nonidet-P40 lysis buffer. The extraction of nuclear and cytosolic fractions from fetal islet was performed using a Pierce Nucleus/Cytosolic kit (Fisher, Nepean, ON, Canada) according to the manufacturer's instructions [24]. Equal amounts $(35 \mu \mathrm{g})$ of extracted proteins from each experimental group were separated by $10 \%$ SDS-PAGE (vol./ vol.) and transferred to a nitrocellulose membrane (Perkin Elmer, Wellesley, MA, USA). Membranes were incubated with appropriate dilutions of primary antibodies (ESM 
Table 2), followed by the application of appropriate horseradish peroxidase-conjugated secondary antibodies (Santa Cruz Biotechnology). Proteins were detected using ECL-Plus western blot detection reagents (Perkin Elmer) and exposed to BioMax MR Film (Kodak, Rochester, NY, USA). Densitometric quantification of bands at subsaturation levels was performed using Syngenetool gel analysis software (Syngene, Cambridge, UK) and normalised to appropriate loading controls, which included the total signalling protein content or housekeeping proteins (calnexin, $\beta$-actin). Data are provided as the relative abundance of phosphorylated proteins to total protein levels or protein levels to the loading control (calnexin, $\beta$-actin) [20, 21].

\section{Real-time RT-PCR}

RNA was extracted from human fetal pancreatic tissues using TRIZOL reagent (Invitrogen). Islet RNA was extracted using an RNAqueous-4PCR kit (Ambion, Austin, TX, USA) $[19,23]$. For each RT reaction, $2 \mu \mathrm{g}$ DNA-free RNA was used with random hexamers/oligo(dT) primers and Superscript reverse transcriptase. Real-time PCR analyses were performed using the iQ SYBR Green Supermix kit in Chromo4 Real time PCR (Bio-Rad). Primers used are listed in ESM Table 3. Relative gene expression was calculated and normalised to the internal standard gene, 18S rRNA, with at least five repeats per age or experimental group [18].

\section{Statistical analysis}

Data are expressed as means \pm SEM. Statistical significance was determined using either the paired Student's $t$ test or one-way ANOVA followed by a post hoc Bonferroni or least significant difference group comparison test. Differences were considered to be statistically significant at $p<0.05$.

\section{Results}

Characterisation of FOXO1 in the developing human fetal pancreas

The spatial and temporal profiles of FOXO1 during human fetal pancreatic development were analysed in 8-12, 14-16 and 18-21 week fetal pancreatic sections [18] (Fig. 1). Double immunostaining revealed FOXO1 localisation in both nuclear and cytoplasmic compartments of human fetal pancreatic cells from the earliest developmental stage ( 8 weeks) in newly differentiated single endocrine (insulin ${ }^{+}$or glucagon $^{+}$) cells budding off from the ducts as well as within the ductal $\left(\mathrm{CK}^{+}{ }^{+}\right)$epithelium (Fig. 1a-c, ESM Fig. 1). Morphometric analyses of nuclear FOXO1 revealed high levels of colocalisation in $\mathrm{CK}_{19}{ }^{+}$, insulin ${ }^{+}$and glucagon ${ }^{+}$cells from 8 to 21 weeks of fetal age (Fig. 1a-c). Moreover, western blotting (Fig. 1d) and qRT-PCR (Fig. 1e) analyses confirmed relatively constant levels of FOXO1 protein and FOXO1 mRNA throughout the 8-21 weeks of fetal pancreatic development.

Co-localisation of FOXO1 with transcription factors in the developing human fetal pancreas

Several studies have demonstrated opposite nuclear vs cytoplasmic localisation of FOXO1 and PDX-1 in murine adult beta cells $[7,8]$. To better understand the subcellular distribution of FOXO1 and PDX-1 during human fetal pancreatic development, double immunofluorescence and morphometric analyses of FOXO1 in $\mathrm{PDX}-1^{+}$cells throughout 8-21 weeks of human fetal pancreatic development were performed. While both cytoplasmic and nuclear FOXO1 staining were observed, morphometric analyses revealed that approximately $50 \%$ of the $\mathrm{PDX}-1^{+}$cells positively stained for $\mathrm{nFOXO1}$ throughout the examined developmental period (Fig. 2a, b), while $\sim 75 \%$ of $\mathrm{NGN}^{+}$ cells contained nFOXO1 (Fig. 2c, d).

Presence of nFOXO1 in proliferating $\left(\mathrm{Ki} 67^{+}\right)$cells during human fetal pancreas development

The majority of studies have demonstrated that FOXO1 inhibits cell proliferation at multiple phases of the cell cycle in various cells and tissues [3, 25-29]. To determine if there is a role for FOXO1 in cell proliferation during human fetal pancreas development, co-localisation of $\mathrm{nFOXO1}$ with Ki67 was assessed (Fig. 3a). A high proportion of Ki67 ${ }^{+}$ cells showed positive staining for $\mathrm{nFOXO1}$ at $8-12$ weeks $(68 \pm 6.5 \%)$, followed by a significant decrease by 14 16 weeks $(31 \pm 5.7 \%, p<0.01$ vs $8-12$ weeks $)$ and $18-$ 21 weeks $(22 \pm 4.2 \%, p<0.001$ vs $8-12$ weeks $)$ of human fetal pancreatic development (Fig. 3b). During these three stages in development, $\sim 3 \%$ of $\mathrm{Ki} 67^{+}$cells consistently demonstrated only cytoplasmic FOXO1.

The effects of insulin or glucose on the subcellular localisation of FOXO1 in human fetal islets

The translocation of FOXO1 between the nucleus and cytoplasm in beta cells has been shown to be regulated through the PI3-kinase/Akt signalling cascade, primarily as a result of growth factor activation $[6,30]$. To determine if growth factors induce movement of FOXO1 between nuclear and cytoplasmic compartments in the human fetal pancreas, isolated islets (18-21 weeks) were incubated with increasing concentrations of either insulin or glucose for 
a
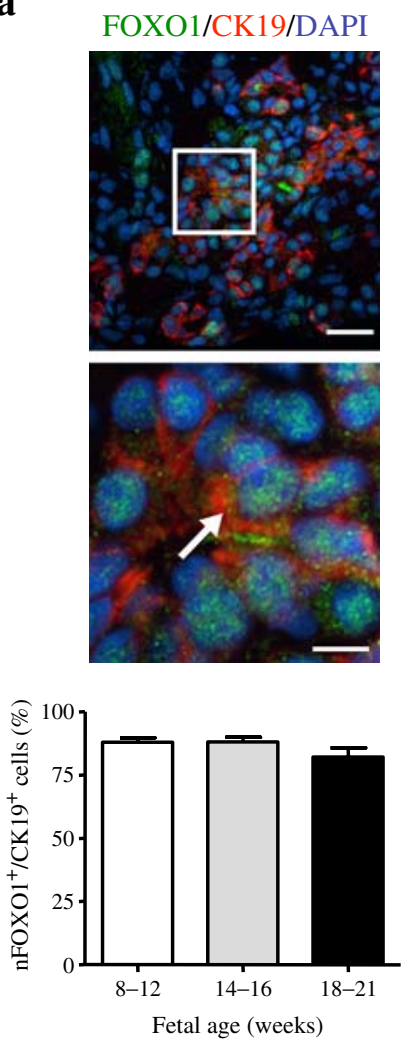

b
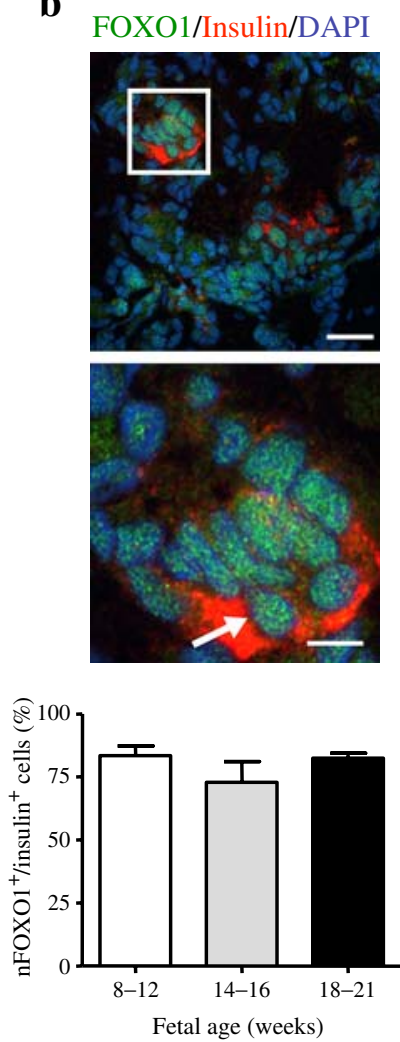

c
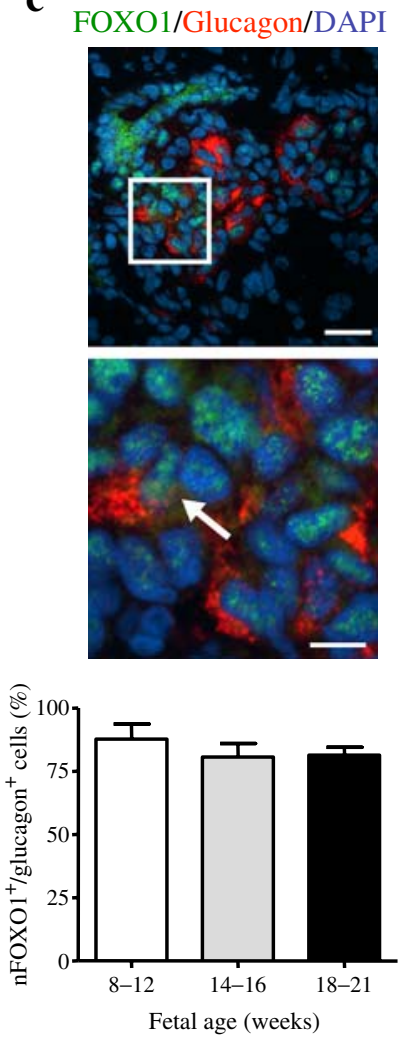

d
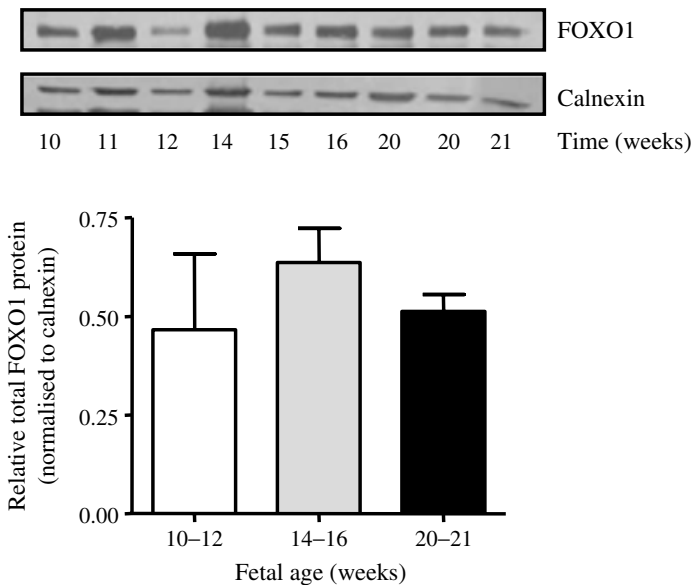

Fig. 1 Expression pattern of FOXO1 during human fetal pancreatic development. a-c Double immunofluorescence of FOXO1 and morphometric analyses of $\mathrm{nFOXO1}$ in cells in ductal and endocrine regions of the developing human pancreas. Representative images for FOXO1 (green) with CK19, insulin or glucagon (red) in a 14 week human fetal pancreas. Nuclei were stained with DAPI. Single-staining channel images are shown in ESM Fig. 1. Scale bar, $100 \mu \mathrm{m}$. Magnified images for each corresponding figure are shown in the bottom of each panel. Scale bar: $10 \mu \mathrm{m}$. Arrows indicate double-positive cells. Bar graphs

24 h. Loss of nFOXO1 within ductal $\left(\mathrm{CK} 19^{+}\right)$cells was observed when the islets were treated with insulin in a dose-dependent manner $(55 \pm 2.8 \%$ at $50 \mathrm{nmol} / 1, p<0.01$; $50 \pm 1.2 \%$ at $100 \mathrm{nmol} / 1, p<0.001$; vs control $76.2 \pm 2.5 \%$ ) $\mathbf{e}$

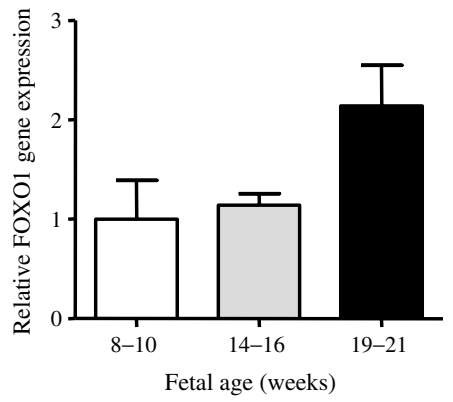

show quantitative analysis of $\mathrm{nFOXO} 1^{+} / \mathrm{CK} 19^{+}, \mathrm{nFOXO} 1^{+} / \mathrm{insulin}^{+}$and $\mathrm{nFOXO}^{+} /$glucagon $^{+}$cells relative to the total number of $\mathrm{CK} 19^{+}$, insulin $^{+}$and glucagon ${ }^{+}$cells counted, respectively. Data are means \pm SEM ( $n=3-6$ pancreases per age group). d Western blot analyses of FOXO1 in human fetal pancreatic tissue. Data are normalised to calnexin and expressed as means \pm SEM $(n=3$ pancreases per age group). e Real-time RT-PCR analysis of FOXO1 mRNA expression. Data are normalised to $18 \mathrm{~S}$ rRNA subunit and expressed as means \pm SEM ( $n=5$ pancreases per age group)

(Fig. 4a), while no effects were observed with glucose treatments (Fig. 4b). In keeping with these results, FOXO1 nuclear localisation within beta cells $\left(\mathrm{C}\right.$-peptide $\left.{ }^{+}\right)$was also significantly reduced $(\sim 30 \%, p<0.05$ vs control) when 
$\mathbf{a}$
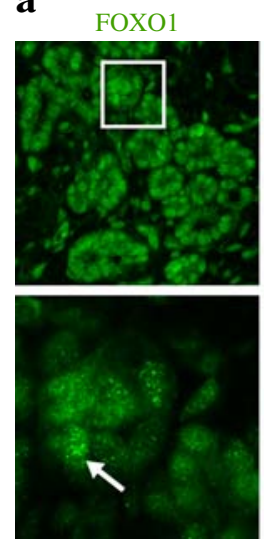

c
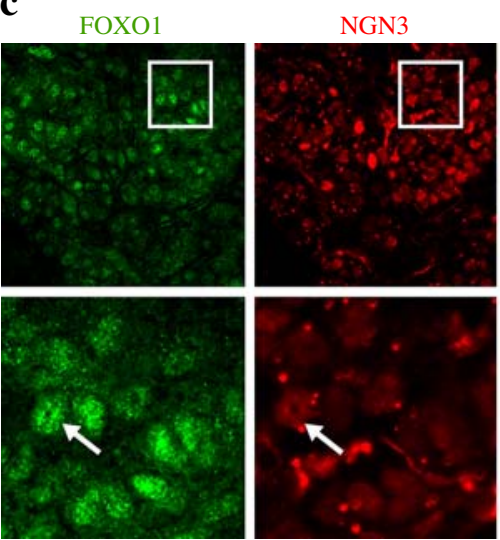

Fig. 2 Co-localisation of FOXO1 with PDX-1 and NGN3 during human fetal pancreatic development. Representative single-staining channel images of co-staining for FOXO1 (green) and PDX-1 (red, a), or NGN3 (red, c) in a 14 week human fetal pancreas. Nuclei were stained with DAPI in (blue). Scale bar, $100 \mu \mathrm{m}$. Magnified images for each corresponding figure are shown in the bottom of each panel.
FOXO1/PDX1/DAPI
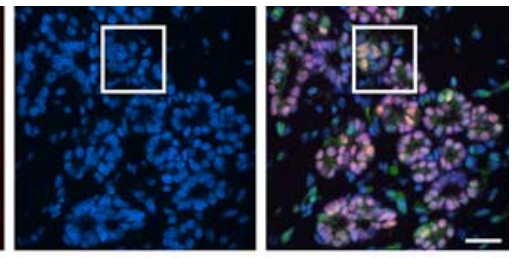

b

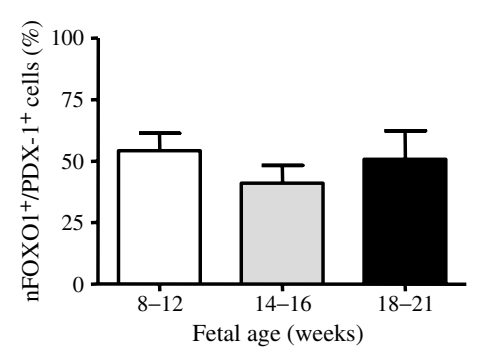

34

FOXO1/NGN3/DAPI

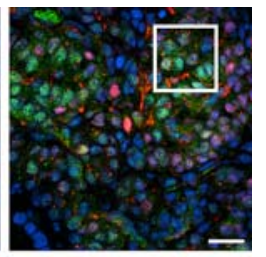

d

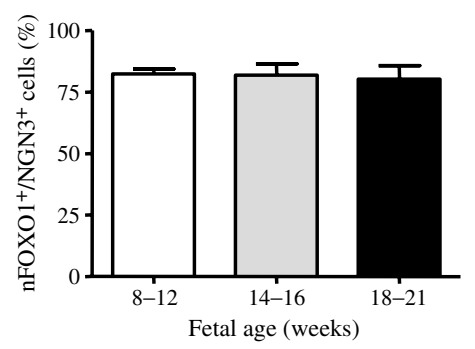

$\mathbf{a}$
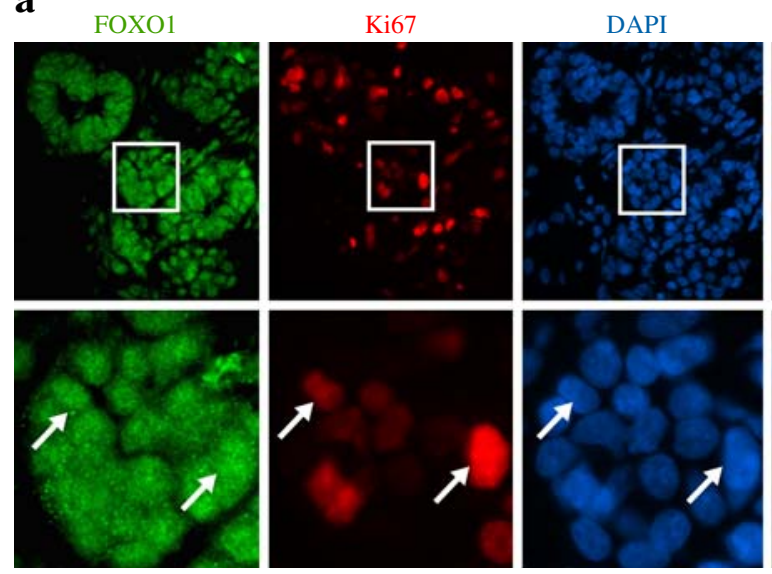

Fig. 3 Co-localisation of FOXO1 with proliferating cells $\left(\mathrm{Ki}^{+} 7^{+}\right)$ during human fetal pancreatic development. Representative singlestaining channel images of FOXO-1 (green) and Ki67 (red) colocalisation at 14 weeks of human fetal pancreatic development (a). Nuclei were stained with DAPI (blue). Scale bar, $100 \mu \mathrm{m}$. Magnified images for each corresponding figure are shown in the bottom of each
Scale bar, $10 \mu \mathrm{m}$. Arrows indicate double-positive cells. Bar graphs show quantitative analysis of $\mathrm{nFOXO} 1^{+} / \mathrm{PDX}-1^{+}$cells relative to the total number of PDX $-1^{+}$cells counted (b) and quantitative analysis of $\mathrm{nFOXO}^{+} / \mathrm{NGN}^{+}$cells relative to the total number of $\mathrm{NGN}^{+}$ cells counted (d). Data are means \pm SEM ( $n=3$ or 4 pancreases per age group)
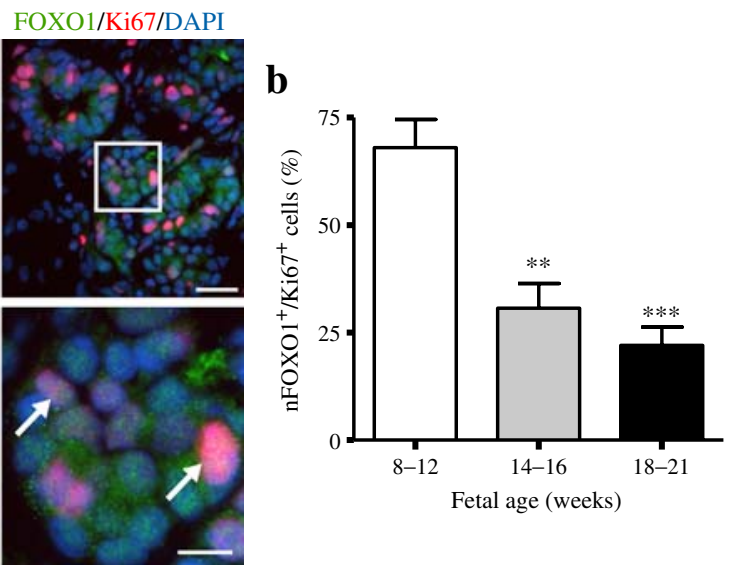

panel. Scale bar, $10 \mu \mathrm{m}$. Arrow indicates double-stained $\mathrm{nFOXO1^{+ } /}$ $\mathrm{Ki}^{+} 7^{+}$cells. Bar graph shows quantitative analysis of $\mathrm{nFOXO} 1^{+} /$ $\mathrm{Ki}^{+} 7^{+}$cells relative to the total number of $\mathrm{Ki}^{+}$cells counted (b). Data are means \pm SEM $(n=3-6$ pancreases per age group; $* * p<0.01$, $* * * p<0.001$ vs $8-12$ weeks) 

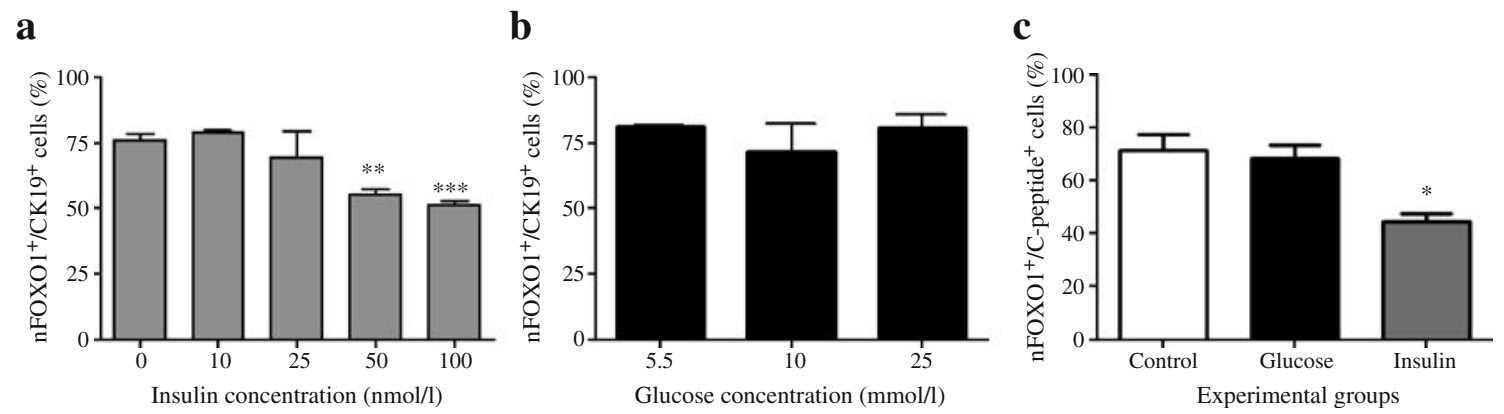

Fig. 4 Effects of insulin or glucose on the subcellular distribution of FOXO1 in islet epithelial cell clusters. Morphometric analysis of nFOXO $1^{+} / \mathrm{CK} 19^{+}$cells relative to the total number of $\mathrm{CK} 19^{+}$cells counted following a $24 \mathrm{~h}$ treatment of $18-21$ week islet epithelial cell clusters with concentrations of insulin (a) or glucose (b) as indicated. Data are means \pm SEM $(n=3$ experiments per treatment group;

$* * p<0.01, * * * p<0.001$ vs control group). c Quantitative analysis of nFOXO $1^{+} / \mathrm{C}_{\text {-peptide }}{ }^{+}$cells relative to the total number of C-peptide ${ }^{+}$ cells counted in the indicated treatment group (control, glucose [25 $\mathrm{mmol} / \mathrm{l}]$, or insulin [50 nmol/l]). Data are means $\pm \operatorname{SEM}(n=3$ experiments per treatment group; ${ }^{*} p<0.05$ vs control and glucose treatment groups)

treated with insulin $(50 \mathrm{nmol} / \mathrm{l})$, but not glucose $(25 \mathrm{mmol} / \mathrm{l})$ (Fig. 4c).

Insulin induces nuclear export of FOXO1 via the PI3kinase/AKT signalling pathway in human fetal islets

To determine if the nuclear export of FOXO1 following insulin stimulation of the islets is mediated via the PI3kinase signalling pathway, alterations in phospho-Akt were examined. Insulin $(50 \mathrm{nmol} / \mathrm{l})$ stimulation resulted in a threefold increase in Akt phosphorylation in comparison with the control group $(p<0.01$, Fig. 5a). To confirm that the PI3-kinase signalling cascade is responsible for the insulin-induced reduction in $\mathrm{nFOXO1}$, human fetal islets were pre-treated with wortmannin $(100 \mathrm{nmol} / \mathrm{l})$. Western blot analysis demonstrated decreased levels of phospho-Akt production upon insulin plus wortmannin co-treatment $(p<0.001$ vs the insulin-treated group, Fig. 5a). Double immunostaining (Fig. 5b) and morphometric analyses (Fig. 5c) revealed that the insulin-induced reduction in nFOXO1 was significantly inhibited by co-treatment with wortmannin in beta cells $\left(C-p e p t i d e^{+}\right)(p<0.05$, Fig. 5c). These results suggest that the insulin-mediated subcellular redistribution of FOXO1 within human fetal islets is at least partially dependent on the PI3-kinase/Akt pathway.

These data were confirmed by western blot analyses of nuclear and cytoplasmic fractions (Fig. $5 \mathrm{~d}-\mathrm{g}$ ). A 50\% decrease in nFOXO1 was observed following insulin stimulation, which was blocked by wortmannin $(p<0.05$, Fig. 5d). There was no significant change in phosphoFOXO1 ${ }^{\text {Ser256 }}$ levels in the cytoplasmic fractions (Fig. 5e) or in total cellular FOXO1 abundance in the treated groups (Fig. 5f). A lack of significant alterations in cytosolic FOXO1 levels may be attributable to partial FOXO1 degradation [31, 32]. Western blotting for phosphoFOXO1 ${ }^{\text {Ser256 }}$ showed that phospho-FOXO1 was only present in the cytoplasm (Fig. $5 \mathrm{~g}$ ). These results indicate that FOXO1 is subject to insulin inhibition by undergoing insulin-dependent phosphorylation and nuclear exclusion in the developing human fetal pancreas.

Knockdown of FOXO1 mRNA levels promotes beta cell differentiation in human fetal islets

The effects of downregulating FOXO1 levels in human fetal islets were examined using siRNA technology. qRTPCR (Fig. 6a), immunostaining (Fig. 6b) and western blot analyses (Fig. 6c, d) confirmed knockdown of FOXOI following transient transfection of siRNA after $48 \mathrm{~h}$ of culture when compared with controls. Cells treated with FOXO1 siRNA showed a reduction not only in nFOXO1 but also in cytoplasmic FOXO1 (Fig. 6b). Interestingly, knockdown of $F O X O 1$ gene expression induced a significant increase in insulin mRNA levels ( $p<0.03$ vs control) (Fig. 6e) and in the number of C-peptide ${ }^{+}$cells $(p<0.05$ vs control) (Fig. 6f) in comparison with control siRNA groups, but had no affect on the number of glucagon ${ }^{+}$cells (data not shown). The proliferation capacity of the islets following FOXO1 siRNA transfection was examined: we found a $\sim 50 \%$ increase in the number of $\mathrm{Ki}^{2} 7^{+}$cells in the $\mathrm{FOXO1}$ siRNA group that was not statistically significant (ESM Fig. 2).

To analyse the effects of downregulating FOXO1 on transcription factors essential for beta cell development, NGN3 and its associated upstream and downstream transcription factors were examined. There was an approximately twofold increase in $N G N 3$ mRNA levels in the FOXO1 siRNA-transfected group $(p<0.05$, Fig. $7 \mathrm{a})$, in parallel with a fourfold increase in the number of $\mathrm{NGN3}^{+}$ cells $(p<0.001$, Fig. 7 c, e). We also detected a 1.7 -fold increase in NKX6-1 mRNA levels in the FOXO1 siRNA group, but this did not reach statistical significance in 
a

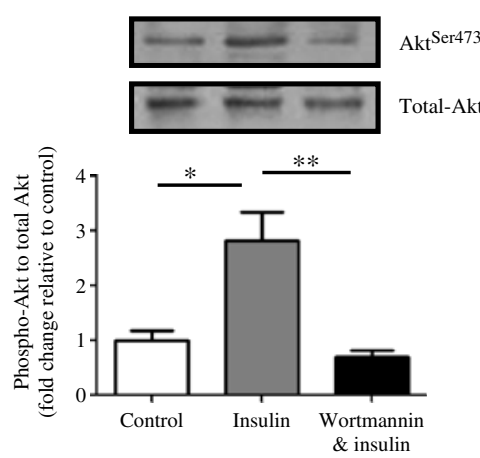

b

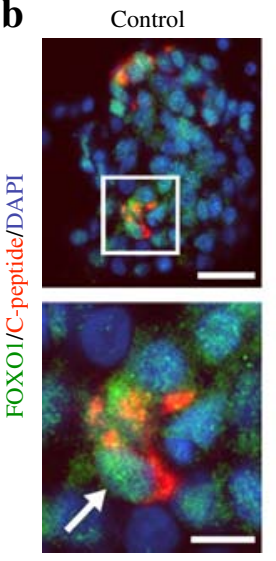

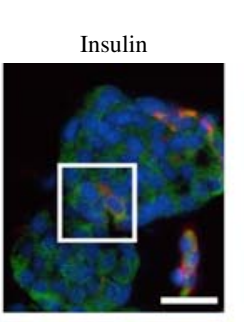

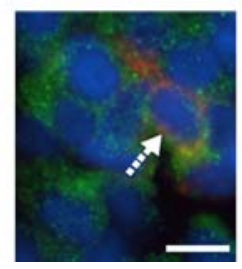

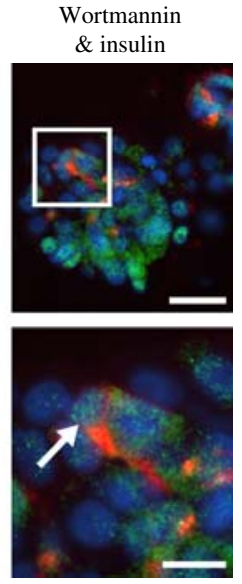

d

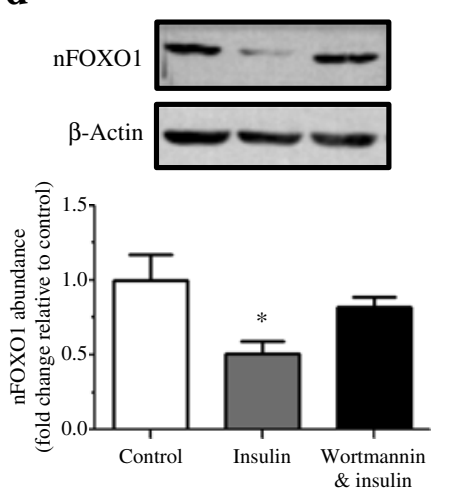

e

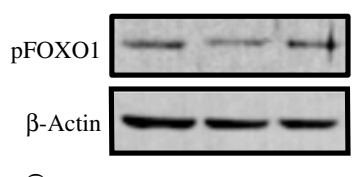

$\mathbf{f}$

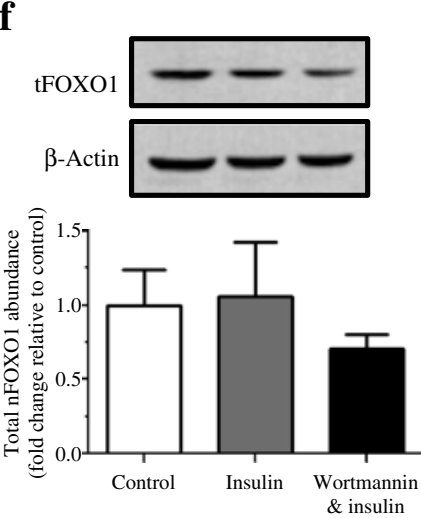

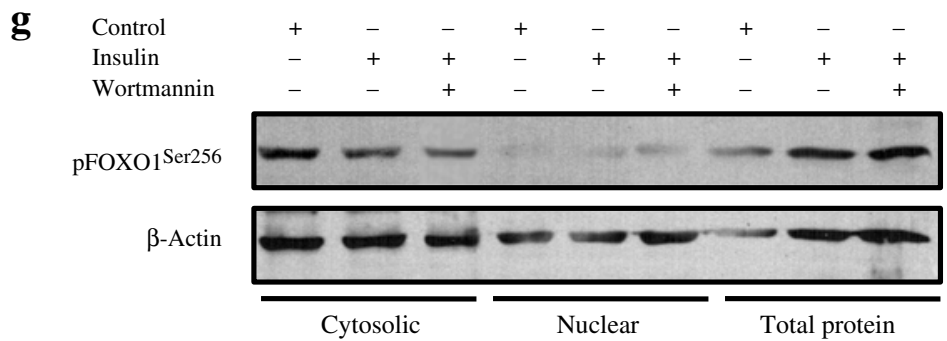

Fig. 5 Insulin affects the subcellular distribution of FOXO1 via activation of the PI3-kinase/Akt pathway. a Western blot analysis of phospho-Akt ${ }^{\mathrm{Ser} 473}$ and total Akt in islet epithelial cell clusters following control, insulin $(50 \mathrm{nmol} / \mathrm{l})$ or wortmannin $(100 \mathrm{nmol} / \mathrm{l})$ and insulin $(50 \mathrm{nmol} / \mathrm{l})$ treatments for $24 \mathrm{~h}$. Representative blots are displayed. Data were normalised to total Akt and expressed as means \pm SEM ( $n=3$ experiments per treatment group). b Double immunofluorescence of FOXO1 (green) and C-peptide (red) in isolated human fetal islet epithelial cell clusters following $24 \mathrm{~h}$ control, insulin or wortmannin and insulin treatments. Nuclei were stained with DAPI (blue). Scale bar, $100 \mu \mathrm{m}$. Magnified images for each corresponding figure are shown in the bottom of each panel.
Scale bar, $10 \mu \mathrm{m}$. Arrows indicate $\mathrm{nFOXO} 1^{+} / \mathrm{C}$-peptide ${ }^{+}$cells and

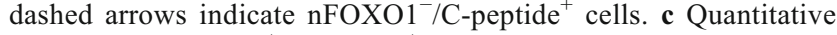
analysis of $\mathrm{nFOXO} 1^{+} / \mathrm{C}$-peptide ${ }^{+}$cells relative to the total number of C-peptide ${ }^{+}$cells counted in the control, insulin and wortmannin and insulin experimental groups. Data are means \pm SEM $(n=4$ experiments per treatment group). Western blot analysis of nFOXO1 (d), cytoplasmic FOXO1 (e), total cellular FOXO1 $(\mathrm{tFOXO1})(\mathbf{f})$, FOXO1 $(\mathbf{d}, \mathbf{f})$ and phospho $(\mathrm{p})-\mathrm{FOXO} 1^{\mathrm{Ser} 256}(\mathbf{e}, \mathbf{g})$ levels in each experimental group. Representative blots are displayed. Data were normalised to $\beta$-actin and expressed as means $\pm \operatorname{SEM}(n=3$ or 4 experiments per treatment group). ${ }^{*} p<0.05,{ }^{* *} p<0.01$ vs control and wortmannin and insulin groups comparison with controls (Fig. 7b). However, FOXO1 siRNA treatment resulted in a threefold increase in NKX6- $1^{+}$cells $(p<0.05$, Fig. $7 d$, f). In contrast, no changes were detected in the cellular distribution or mRNA levels of ISL LIM homeobox 1 (ISL1), NK2 homeobox 2 (NKX2-2) and paired box gene 6 (PAX6) in FOXO1 siRNA- transfected groups (ESM Fig. 3). Furthermore, there were no differences in the cellular distribution of PDX-1 (Fig. 8a) and no changes in either $P D X-1$ mRNA (Fig. 8b) or protein (Fig. 8d) levels following FOXO1 siRNA. In contrast, FOXO1 siRNA treatment resulted in a significant decrease in nHES1 abundance compared with 


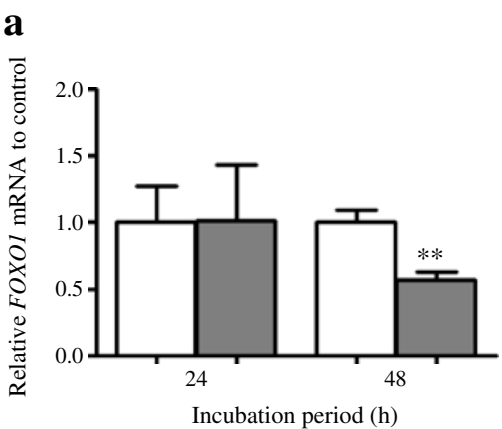

d

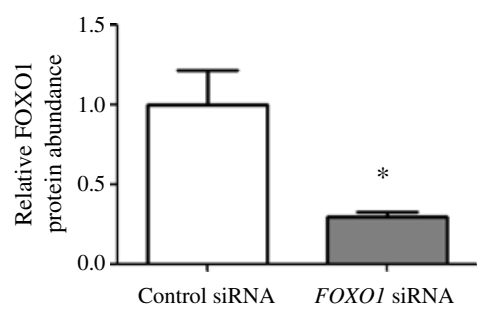

b

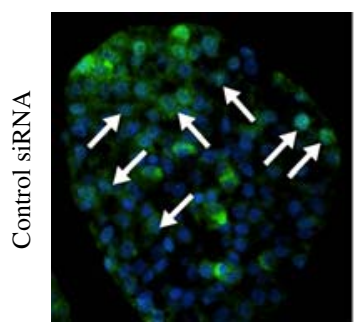

e

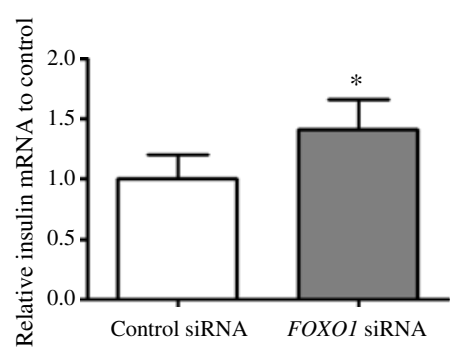

c

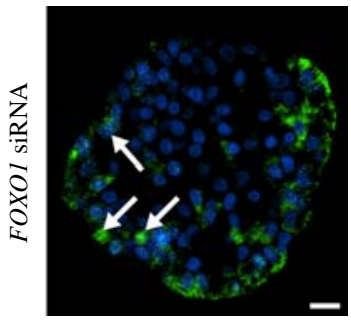

FOXO1

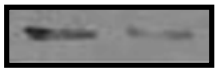

Calnexin

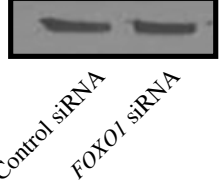

f

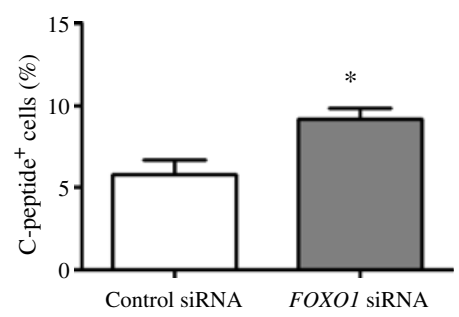

Fig. 6 Effect of FOXO1 siRNA on total FOXO1 mRNA, FOXO1 protein levels and beta cell differentiation in islet epithelial cell clusters. a qRT-PCR analysis of total FOXO1 mRNA expression in islet epithelial cell clusters transfected with either control or FOXO1 siRNA for 24 or $48 \mathrm{~h}$. Data were normalised to $18 \mathrm{~S}$ rRNA and are expressed as means \pm SEM $\left(n=6\right.$ experiments per treatment group; ${ }^{* *} p<0.01$ vs $48 \mathrm{~h}$ control siRNA group). b Immunofluorescence analyses of FOXO1 (green) in human fetal islet cells following control or FOXO1 siRNA transfection for $48 \mathrm{~h}$. Nuclei are stained with DAPI. Scale bar, $10 \mu \mathrm{m}$. Arrows indicate $\mathrm{FOXO}^{+}$cells. c, d Western blot analysis of total

controls (Fig. 8a). Consistent with this observation, we detected a twofold reduction in HESI mRNA and protein levels by qRT-PCR $(p<0.05$, Fig. $8 \mathrm{c})$ and western blotting $(p<0.01$, Fig. 8 e) .

\section{Discussion}

The present study demonstrates that the transcription factor FOXO1 is present in the human fetal pancreas during weeks 8-21 of fetal life, localised in cells producing ductal and endocrine cell markers. When challenged with $50 \mathrm{nmol} / 1$ insulin, 18-21 week fetal islet cells displayed a loss of FOXO1 from the nuclear compartment, indicating that insulin regulation of FOXO1 is functional at an early developmental stage. More importantly, siRNA knockdown of FOXO1 resulted in increases in NGN3, NKX6-1 and insulin gene expression in parallel with increases in the $\mathrm{NGN}^{+}, \mathrm{NKX}-1^{+}$and C-peptide ${ }^{+}$cell populations. These data suggest that FOXO1 may have a significant role in inhibiting beta cell differentiation during human fetal pancreatic development.

FOXO1 presence in the nucleus has been shown to be indicative of biological activity [9]. Our immunohistochem-
FOXO1 protein levels of islet epithelial cell clusters treated with either control or FOXO1 siRNA for $48 \mathrm{~h}$. Data were normalised to calnexin and are expressed as means \pm SEM $(n=4$ experiments per treatment group; ${ }^{*} p<0.05$ vs $48 \mathrm{~h}$ control siRNA group). Representative blots are displayed. qRT-PCR analyses of total insulin mRNA level (e) and the percentage of $\mathrm{C}$-peptide ${ }^{+}$cells (f) in human fetal islet epithelial cell clusters treated with either control or FOXO1 siRNA for $48 \mathrm{~h}$. Data are means \pm SEM ( $n=5$ or 6 experiments per treatment group; $* p<0.05$ vs control siRNA group)

ical analyses demonstrated relatively constant levels of nFOXO1 in both ductal and islet cell populations of the 821 week human fetal pancreas. Moreover, nFOXO1 was highly co-localised with $\mathrm{PDX}-1^{+}$and $\mathrm{NGN}^{+}$cell populations during this developmental period. These findings are consistent with observations in the mouse, where FOXO1 is widely produced between e9.5 and 14.5 [10-14], a stage corresponding to the human developmental window examined in the present study. However, following this period in the mouse, a global decline in the distribution of FOXO1 has been observed, whereby this transcription factor becomes restricted to endocrine progenitor cells by e17.5 and eventually becomes limited to beta cells postnatally $[12,13]$.

The presence of $\mathrm{nFOXO1}$ in multiple endocrine progenitor and differentiating cell types during early murine and human fetal pancreatic ontogeny suggests that this transcription factor performs a global function in these cells. In rodent beta cells, FOXO1 controls various cellular responses including proliferation [4, 26-29]. Our ex vivo analyses demonstrated a progressive decrease in the localisation of $\mathrm{nFOXO1}$ within proliferating cells, suggesting that FOXO1 may be involved in regulating cell cycle progression in the human fetal pancreas after 12 weeks of 


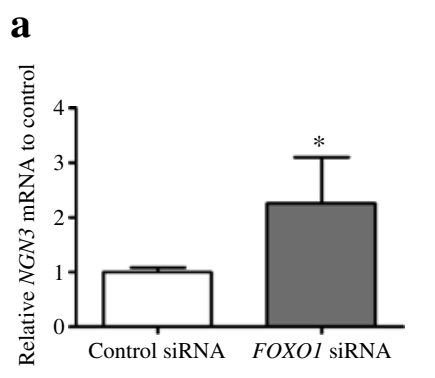

e

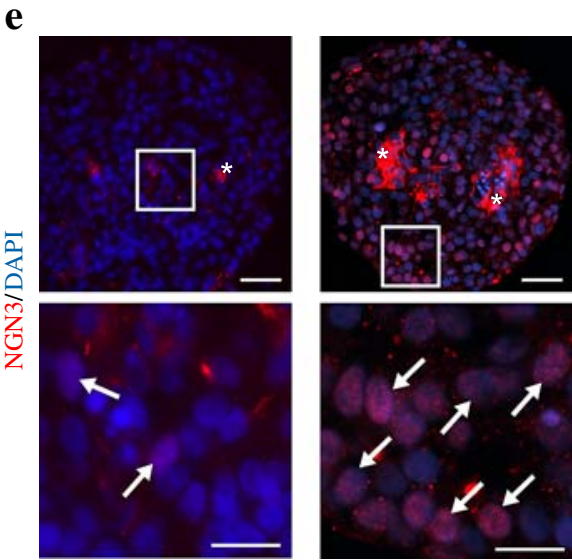

Fig. 7 Knockdown of FOXO1 increases NGN3 and NKX6-1 mRNA expression in islet epithelial cell clusters. qRT-PCR analysis of $N G N 3$ (a) and NKX6-1 (b) mRNA expression in islet epithelial cell clusters transfected with either control or FOXO1 siRNA for $48 \mathrm{~h}$. Data are means \pm SEM $\left(n=4\right.$ experiments per treatment group; ${ }^{*} p<0.05$ vs control siRNA group). The number of $\mathrm{NGN3}^{+}$(c) or $\mathrm{NKX6}^{+}-^{+}$(d) cells in islet epithelial cell clusters transfected with either control or FOXO1 siRNA for $48 \mathrm{~h}$. Data are the percentage of $\mathrm{NGN}^{+}$or

fetal age. However, the proliferation index was not significantly upregulated following FOXO1 siRNA transfection. Although this may be due to insufficiency of the knockdown or the fetal stage at which the siRNA studies were carried out, our present data suggest a more important role for FOXO1 in cell differentiation during human fetal pancreas development.

The most prominent role for FOXO1 in adult beta cells is negative transcriptional regulation of PDX-1 [4, 7, 33]. This mechanism is reversed by Akt-induced FOXO1 phosphorylation and nuclear export, thereby allowing FOXA2-induced $P D X-1$ expression [7, 34]. In adult murine beta cells, a separate subcellular localisation for FOXO1 and PDX-1 has been reported: FOXO1 is found in the cytoplasm while PDX-1 is localised to the nucleus $[4,7]$. However, in 8-21 week human fetal pancreases, FOXO1 and PDX-1 were co-localised within the nucleus. Furthermore, knockdown of FOXO1 mRNA in the fetal islets had no effect on either total mRNA or protein levels or the nuclear localisation of PDX-1. These data suggest that FOXO1 may regulate PDX-1 differently during human c

d
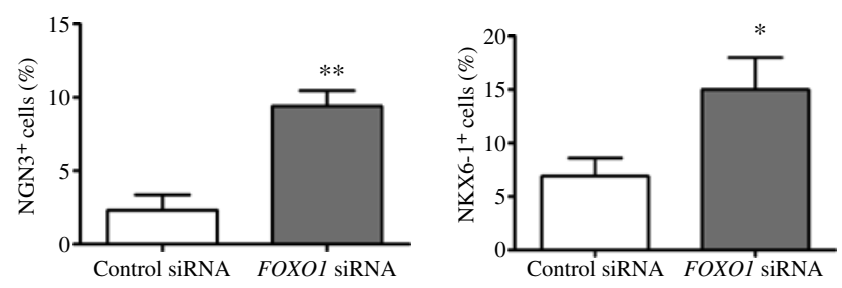

f

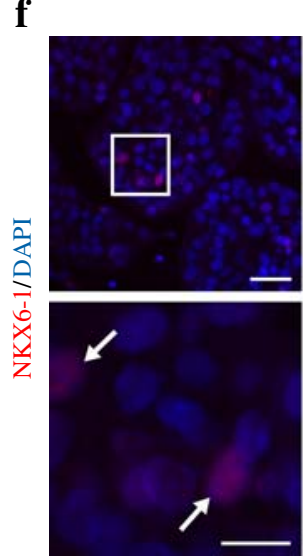

Control siRNA

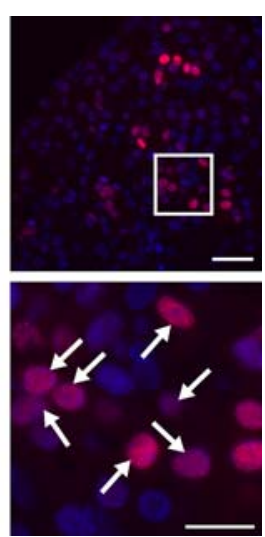

FOXO1 siRNA
NKX6- $1^{+}$cells (means \pm SEM, $n=5$ experiments per treatment group; ${ }^{*} p<0.05, * * p<0.01$ vs control siRNA group). Double immunofluorescence analyses of NGN3 (e) and NKX6-1 (f) (red) in human fetal islet epithelial cell clusters transfected with either control or FOXO1 siRNA for $48 \mathrm{~h}$. Nuclei were stained with DAPI (blue). Scale bar, $100 \mu \mathrm{m}$. Magnified images for each corresponding figure are shown in the bottom of each panel. Scale bar, $10 \mu \mathrm{m}$. Arrows indicate $\mathrm{NGN}^{+}$or NKX6-1 $1^{+}$cells, asterisks indicate neural cells

pancreatic development than in adult beta cells, or that it performs a role independent of PDX-1 regulation.

Numerous reports have established that altering the nutritional status of beta cells is associated with changes in FOXO1 transcriptional activity via the PI3-kinase pathway $[6,30,35]$. FOXO1 is a key effector of insulin action in beta cells, especially in the regulation of beta cell mass $[7,36]$. To investigate if this also applies to cells of the developing human pancreas, the effects of exogenous and endogenous insulin (addition of glucose) were tested. Exogenous insulin at $50 \mathrm{nmol} / 1$ stimulated a $~ 50 \%$ reduction in the nuclear localisation of FOXO1. This level of translocation is lower than has been observed in murine beta cells, presumably due to the dose of insulin used and/ or suboptimal sensitivity of fetal cells to the insulin stimulation, as doubling the insulin dose caused a small further reduction in the nFOXO1 level. However, a highglucose stimulation had no obvious effect on the translocation of FOXO1. This is in direct contrast to results reported for adult mouse beta cells where high glucose concentrations increased the nuclear translocation of 
a
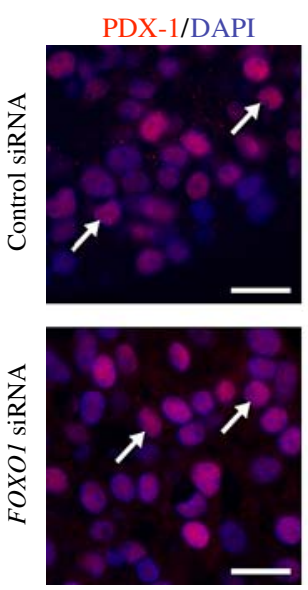

b

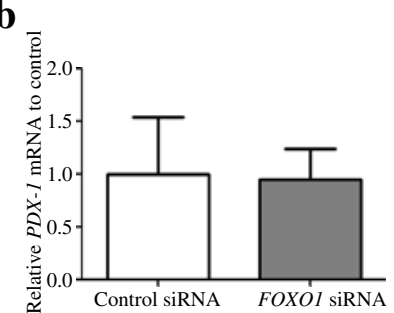

d
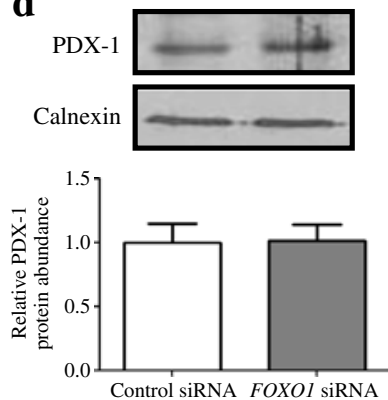

HES1/DAPI
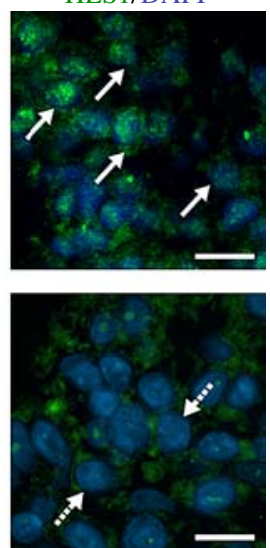

c

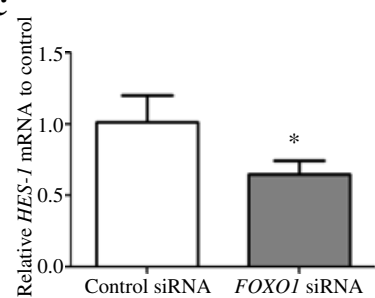

e
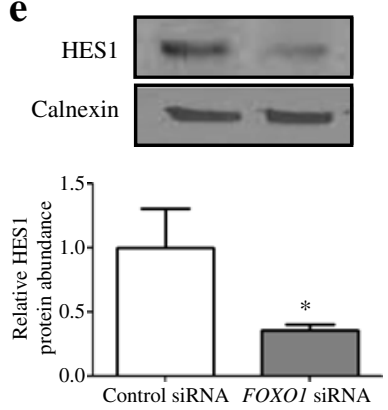

Fig. 8 Knockdown of FOXO1 does not affect PDX-1 levels but downregulates HES1 in human islet epithelial cell clusters. a Double immunofluorescence analyses of PDX-1 (red) or HES1 (green) in human fetal islet epithelial cell clusters transfected with either control or FOXO1 siRNA for $48 \mathrm{~h}$. Nuclei were stained with DAPI (blue). Scale bar, $10 \mu \mathrm{m}$. Arrows indicate the nuclear PDX $-1^{+}$or $\mathrm{HES} 1^{+}$cells and dashed arrows indicate the cytoplasmic HES1-stained cells. Total PDX-1 (b) or HES1 (c) mRNA levels by qRT-PCR and protein levels by western blot (d, e) analyses of human fetal islet epithelial cell clusters transfected with either control or FOXO1 siRNA for $48 \mathrm{~h}$. Data are means \pm SEM $(n=6$ experiments per treatment group for the qRT-PCR assays, $n=4$ experiments per treatment group for the western blots; ${ }^{*} p<0.05$ vs control siRNA group)

FOXO1 as part of an anti-oxidative stress response mechanism [9]. Thus, our findings indicate that either glucose/insulin signalling is not fully functional at 1821 weeks or that glucose signalling is not sufficient to bring about any effect on FOXO1 subcellular localisation. Finally, the insulin-induced FOXO1 response was inhibited by the addition of wortmannin, indicating that FOXO1 translocation in the developing human fetal islet

epithelial cells is mediated through the PI3-kinase/Akt signalling cascade [6].

In order to identify a specific role for FOXO1 in human fetal islets, the effects of $F O X O 1$ knockdown via siRNA were examined. Knockdown led to notable increases in the beta cell population as well as insulin mRNA levels, indicating that FOXO1 may be involved in beta cell differentiation during human fetal pancreatic development. These findings are in accord with a recent study reporting a selective increase in juxta-ductal beta cells following a conditional Foxol knockdown in pancreatic progenitors in $P d x$-1-cre mice [13].

Upregulation of the NGN3 and NKX6-1 cell populations also occurred following $\mathrm{FOXO1}$ gene knockdown in the islets, while there was no change in the abundance of other transcription factors critical for pancreatic islet cell differentiation, including ISL1, NKX2-2 and PAX6 [2]. These results are supported by our previous finding of a parallel decrease in $N G N 3$ and $N K X 6-1$ expression from 8 21 weeks of human fetal pancreatic development while ISL1, NKX2-2 and PAX6 increased significantly [18]. In addition, we have observed that NKX6-1 is produced only in beta cells in the human fetal pancreas [18], indicating that NKX6-1 probably plays a significant role that is different from other transcription factors during human fetal beta cell development.

Co-localisation of FOXO1 and NGN3 has been observed in both human and mouse models [13]. Downregulation of FOXO1 mRNA in human fetal islets resulted in a significant upregulation of $N G N 3$ mRNA levels and the number of $\mathrm{NGN}^{+}$cells, suggesting that $N G N 3$ may be a potential target for FOXO1. In support of this, a cluster of binding sites for forkhead factors, including FOXA2, was recently identified in the distal region of the $N G N 3$ promoter [16]. In murine adult islets, FOXA2 competes with FOXO1 for the same binding site within the $P d x-1$ promoter to regulate $P d x-1$ expression [7]. It will be interesting in future experiments to investigate if control of $N G N 3$ transcription during human fetal pancreatic development involves a similar forkhead factor-dependent mechanism.

The Notch signalling pathway has been reported to prevent Ngn3 expression in the majority of duct cells during murine pancreatic development [37]. Disruption of Notch signalling or its downstream mediators, including HES1, causes widespread expression of Ngn3 in the murine pancreas and accelerated endocrine differentiation [38, 39]. Following FOXO1 silencing, a significant decrease in HES1 gene expression and protein abundance was observed in the human fetal islets. These findings are in accord with a recently proposed mechanism describing a functional interaction between FOXO1 and Notch that is required for the regulation of myoblast maintenance and differentiation 
[15]: this model suggests that murine FOXO1 binds to the CSL element within the Hes 1 promoter, stabilising the Notch/CSL complex, and thereby enhancing Hes 1 transcription [15]. Thus, our present study suggests a second possible mechanism by which FOXO1 may regulate NGN3 levels during human pancreatic development.

In summary, we have investigated the cellular localisation and potential function of FOXO1 in the early to mid-gestation human fetal pancreas. Its broad expression pattern in multiple endocrine precursor and differentiating cell types along with its inhibitory effects on factors critical for beta cell differentiation suggest that FOXO1 performs key global as well as highly specialised functions in the human fetal pancreas. These data also indicate that manipulation of FOXO1 levels may prove to be a useful tool for the development of more effective cell-based therapies for diabetes treatment.

Acknowledgements This work was supported by grants from the Canadian Diabetes Association. R. Wang is supported by a New Investigator Award from the Canadian Institute of Health Research. We thank the Department of Pathology at London Health Science Centre for providing human fetal pancreatic tissue sections.

Duality of interest The authors declare that there is no duality of interest associated with this manuscript.

\section{References}

1. Shapiro AM, Lakey JR, Ryan EA et al (2000) Islet transplantation in seven patients with type 1 diabetes mellitus using a glucocorticoidfree immunosuppressive regime. N Engl J Med 343:230-238

2. Habener JF, Kemp DM, Thomas MK (2005) Minireview: transcriptional regulation in pancreatic development. Endocrinology $146: 1025-1034$

3. Huang H, Tindall DJ (2007) Dynamic FoxO transcription factors. J Cell Sci 120:2479-2487

4. Buteau J, Accili D (2007) Regulation of pancreatic beta-cell function by the Forkhead protein FoxO1. Diabetes Obes Metab 9 (Suppl 2):140-146

5. Harbeck MC, Louie DC, Howland J, Wolf BA, Rothenberg PL (1996) Expression of insulin receptor mRNA and insulin receptor substrate 1 in pancreatic islet beta-cells. Diabetes 45:711-717

6. Brunet A, Bonni A, Zigmond MJ et al (1999) Akt promotes cell survival by phosphorylating and inhibiting a Forkhead transcription factor. Cell 96:857-868

7. Kitamura T, Nakae J, Kitamura Y et al (2002) The forkhead transcription factor foxo1 links insulin signaling to $\mathrm{Pdx} 1$ regulation of pancreatic beta cell growth. J Clin Invest 110:1839-1847

8. Kawamori D, Kaneto H, Nakatani Y et al (2006) The forkhead transcription factor Foxol bridges the JNK pathway and the transcription factor Pdx-1 through its intracellular translocation. J Biol Chem 281:1091-1098

9. Kitamura YI, Kitamura T, Kruse JP et al (2005) FoxO1 protects against pancreatic beta cell failure through NeuroD and MafA induction. Cell Metab 2:153-163

10. Ahlgren U, Jonsson J, Edlund H (1996) The morphogenesis of the pancreatic mesenchyme is uncoupled from that of the pancreatic epithelium in IPF/PDX1-deficient mice. Development 122:14091416

11. Guz Y, Montminy MR, Stein R et al (1995) Expression of murine STF-1, a putative insulin gene transcription factor, in beta cells of pancreas, duodenal epithelium and pancreatic exocrine and endocrine progenitors during ontogeny. Development 121:11-18

12. Kitamura T, Ido Kitamura Y (2007) Role of FoxO proteins in pancreatic beta cells. Endocr J 54:507-515

13. Kitamura T, Kitamura YI, Kobayashi M et al (2009) Regulation of pancreatic juxtaductal endocrine cell formation by FoxO1. Mol Cell Biol 29:4417-4430

14. Ohlsson H, Karlsson K, Edlund T (1993) IPF1, a homeodomaincontaining transactivator of the insulin gene. EMBO J 12:42514259

15. Kitamura T, Kitamura YI, Funahashi Y et al (2007) A Foxo/Notch pathway controls myogenic differentiation and fiber type specification. J Clin Invest 117:2477-2485

16. Lee JC, Smith SB, Watada H et al (2001) Regulation of the pancreatic pro-endocrine gene neurogenin 3. Diabetes 50:928-936

17. Hosaka T, Biggs WH, Tieu D et al (2004) Disruption of Forkhead transcription factor (FOXO) family members in mice reveals their functional diversification. Proc Natl Acad Sci U S A 101:29752980

18. Lyttle BM, Li J, Krishnamurthy M et al (2008) Transcription factor expression in the developing human fetal endocrine pancreas. Diabetologia 51:1169-1180

19. Wang R, Li J, Yashpal NK, Fellows F, Goodyer C (2005) Role of betal integrin and its associated $\alpha 3, \alpha 5$ and $\alpha 6$ subunits in the development of the human fetal pancreas. Diabetes 54:2080-2089

20. Li J, Quirt J, Do HQ et al (2007) Expression of c-Kit tyrosine receptor kinase and effect on beta-cell development in the human fetal pancreas. Am J Physiology 293:E475-E483

21. Saleem S, Li J, Yee SP, Fellows F, Goodyer CG, Wang R (2009) beta1 integrin/FAK/ERK signalling pathway is essential for human fetal islet cell differentiation and survival. J Pathol 219:182-192

22. Yashpal NK, Li J, Wheeler MB, Wang R (2005) Expression of $\beta 1$ integrin receptors during rat pancreas development - sites and dynamics. Endocrinology 146:1798-1807

23. Li J, Goodyer CG, Fellows F, Wang R (2006) Stem cell factor/cKit interactions regulate human islet-epithelial cluster proliferation and differentiation. Int J Biochem Cell Biol 38:961-972

24. Kamagate A, Qu S, Perdomo G et al (2008) FoxO1 mediates insulin-dependent regulation of hepatic VLDL production in mice. J Clin Invest 118:2347-2364

25. Tran H, Brunet A, Griffith EC, Greenberg ME (2003) The many forks in FOXO's road. Sci STKE 172:RE5

26. Medema RH, Kops GJ, Bos JL, Burgering BM (2000) AFX-like Forhead transcription factors mediate cell-cycle regulation by Ras and PKB through p27kipl. Nature 404:782-787

27. Nakae J, Kitamura T, Kitamura Y, Biggs WH, Arden KC, Accili D (2003) The forkhead transcription factor foxol regulates adipocyte differentiation. Dev Cell 4:119-129

28. Ramaswamy S, Nakamura N, Sansal I, Bergeron L, Sellers W (2002) A novel mechanism of gene regulation and tumor suppression by the transcription factor FKHR. Cancer Cell 2:81-91

29. Kops GJ, Medema RH, Glassford J et al (2002) Control of cell cycle exit and entry by protein kinase B-regulated forkhead transcription factors. Mol Cell Biol 22:2025-2036

30. Martinez SC, Cras-Meneur C, Bernal-Mizrachi E, Permutt MA (2006) Glucose regulates Foxo1 through insulin receptor signaling in the pancreatic islet beta-cell. Diabetes 55:1581-1591

31. Matsuzaki H, Daitoku H, Hatta M, Tanaka K, Fukamizu A (2003) Insulin-induced phosphorylation of FKHR (Foxo1) targets to proteasomal degradation. Proc Natl Acad Sci U S A 100:1128511290 
32. Huang H, Regan KM, Wang F et al (2005) Skp2 inhibits FOXO1 in tumor suppression through ubiquitin-mediated degradation. Proc Natl Acad Sci U S A 102:1649-1654

33. Gupta D, Leahy AA, Peshavaria M, Leahy JL (2008) Novel mechanism for Foxo1-induced regulation of pdx-1 mRNA expression in mature beta-cells: Foxol inhibition of PPARGamma transcription. Diabetes 57(Suppl 1):A80 (Abstract)

34. Lantz KA, Kaestner KH (2005) Winged-helix transcription factors and pancreatic development. Clin Sci (Lond) 108: 195-204

35. Kops GJ, Dansen TB, Polderman PE et al (2002) Forkhead transcription factor $\mathrm{FOXO} 3 \mathrm{a}$ protects quiescent cells from oxidative stress. Nature 419:316-321
36. Nakae J, Biggs WH, Kitamura T et al (2002) Regulation of insulin action and pancreatic beta-cell function by mutated alleles of the gene encoding forkhead transcription factor Foxo1. Nat Genet $32: 245-253$

37. Murtaugh LC, Stanger BZ, Kwan KM, Melton DA (2003) Notch signaling controls multiple steps of pancreatic differentiation. Proc Natl Acad Sci U S A 100:14920-14925

38. Apelqvist A, Li H, Sommer L et al (1999) Notch signaling controls pancreatic cell differentiation. Nature 400:877-881

39. Jensen J, Heller RS, Funder-Nielsen T et al (2000) Independent development of pancreatic alpha- and beta-cells from neurogenin3-expressing precursors: a role for the notch pathway in repression of premature differentiation. Diabetes 49:163-176 